\title{
Into the vortex: female voice and paradox in film
}

Britta Sjogren, University of Illinois Press, Urbana and Chicago, 2006, 248pp, ISBN 0-252-07267-7, £14.99

Britta Sjogren's search for feminine subjectivity as a 'positive structuring element' in 1940s films rather than as a 'subversive thread' (p. 2) may, from the outset, seem like a rather ambitious task. Especially when considering her avowed intent to 'question, refute, and rebut some strongly entrenched theoretical assumptions that have led many feminist (and other) critics to dismiss Hollywood films as invariably and monolithically "male-centred"'. Describing the ways in which this system caters 'to a phallocentric gaze alone, as occluding the feminine, and as containing the woman, and her desire, not only within images that objectify her, but also inside narrative structures that construct and oppress her subjectivity and point of view' (p. 1), Sjogren's approach theorizes an alternative discourse, one that privileges sound over image.

The necessity of engaging with some heavy theoretical territory soon becomes clear if Sjogren's search for a feminine subjectivity within classical Hollywood films is to be a success. That she is qualified for the job is never in question. As a feminist filmmaker she certainly knows how sound works in film and soon proves herself more than capable of applying that practical knowledge to a theoretical investigation into the female voice in 1940 s Hollywood films. Particularly those that contain a voiceover - or voice-off as she calls it - as examples of how 'the voice offers another perspective, a subject placement that allows for multiple subjectivities, rather than "centering" just One' (p. 10).

While acknowledging a huge debt to Kaja Silverman and Mary Ann Doane for their work on the female voice in film, Sjogren takes issue with the demarcations they apply and suggests that the very hierarchies Doane and Silverman impose onto the voice in film '[invites] us to forget the alterity that is always present' (p. 7). Sjogren's project here is to refer to these 'very taxonomies' throughout the book as 'particularly useful in helping to "visualize" aspects of the voice's multiple spatiality in relation to imaged space' in her effort to 'preserve and foreground' this otherness, this 'residue of difference and plurality of which the voice speaks' (p. 7).

What follows is a meticulous investigation into sound in film. Sjogren critiques the privileging of image over sound as innately flawed, arguing that theorists may have come to some kind of consensus regarding the 'heterogeneity sound presents to image' ( $p .10$ ) but that they fall into either one of two camps. The first in which sound is assumed to be just like the image, 'though subservient to it in many ways' or, the second with sound 'posing a potentially radical difference ... viewed as constrained by being embedded within the image' 
(p. 11). The main problem for Sjogren is that both camps fail to release sound from its inferior relationship to the image. In her words, 'For all these theorists, cinema is, indeed, primarily a visual art' (p. 11).

For me this is the major problem with Sjogren's work. Despite the fact that she should be applauded for keeping 'an open mind about the possibility for any voice - embodied or not - to speak of the feminine' (p. 9) and releasing sound from its neglected status in film theory, I found the book laboured in places. As if, in order to release sound from its very embeddedness in the image, Sjogren, at times, overstates her case. As much as her reading of the voice-off in 1940s films opens up and theorizes female subjectivity to a more feminist interpretation, I worry that her intention to overthrow the primacy of the visual in film studies was problematic in itself, adding another 'bias' to those she was attempting to overcome. Regardless of how excited I was at the outset of Sjogren's book and the importance of her intervention for feminist film theory, I found myself sympathizing with those theorists that insist that cinema is, by its very nature, first and foremost a visual art.

Her study of the main films in question, Letter to an Unknown Woman (Max Ophuls, 1948), Secret Behind the Door (Fritz Lang, 1948) and A Letter to Three Wives (Joseph L. Mankiewicz, 1949) is insightful and her application of the 'metapsychology of the voice-off' is useful for a renewed understanding of how sound works in film and how a feminine subjectivity can be theorized. But, as useful as her intervention in feminist film theory is, particularly in the relatively under-theorized area of sound in film, I do wonder if Sjogren would be better moving beyond films of the 1940s. The author herself posits this thought when, in interrogating and problematizing Silverman's theories of the voice-off she ponders: 'it would seem that some hope yet remains for the female voice-off, which, in the right hands, still has something to offer the female spectator (or filmmaker)' (p. 49). My hope is that Sjogren will (continue to) utilize her theories not only in her own filmmaking but also in analysing more modern texts.

Into the Vortex is definitely a book worth reading, a useful intervention in the field of sound in cinema and, despite my reservations, one I would recommend for inclusion on University reading lists.

Kim Akass

doi: $10.1057 / \mathrm{fr} .2009 .16$ 